\title{
A REVIEW ON OPTIMAL DESIGN OF MAGNETO-RHEOLOGICAL DAMPER
}

\author{
DANIEL. C, HEMALATHA. G, ARUNRAJ. E, \\ VINCENT SAM JEBADURAI. S \& SARALA. L
}

Karunya Institute of Technology and Sciences, Coimbatore, Tamil Nadu, India

\begin{abstract}
In recent years, research works are done mostly in the field of Semi-Active Control systems, like Magneto Rheological dampers to reduce the effect of seismic vibrations in the structures. In this paper, researchers working in optimal design of MR dampers using various developed control Algorithms, propose the most efficient model of MR fluid, done by comparing various primary design parameters, and the variation of each parameter with respect to the other has been studied in detail. Optimal Design of MR dampers to resist the maximum damping force, in order to have reduced vibrations and hence, the validation of results for the maximum damping force and damping displacements mainly depends upon the application of an external magnetic field or no field i.e Rheology On-State and Off-State. The study on various configurations of design of analytical methods have been done.
\end{abstract}

KEYWORDS: Magneto-Rheological Damper (MR), ANSYS Parametric Design Language (APDL), ProportionalIntegral-Derivative Control (PID) \& Linear Quadratic Regulator Control (LQR)

Received: Sep 10, 2018; Accepted: Oct 01, 2018; Published: Nov 26, 2018; Paper Id.: IJMPERDDEC201860

\section{INTRODUCTION}

Today, most of the civil engineers are challenged to construct structures that are well protected. Researchers are finding out ways and means to protect their structures and its component elements from the hazardous effect such as Earthquakes, Smart methods like use of Semi-Active control systems and strategies [6],11],[14],[15],[18].To dissipate or deflect the structural vibration energy has been one of the promising approaches to protect the structures under seismic vibrations. Semi-Active control approach offers a significant adaptive with lower power consumption [5]. Researchers have developed lot of control algorithms [10],[13],[15] based on acceleration feedback for the MR damper.This paper, highlights the work done in the area of optimal designing of MR dampers [7],[16],[17] for Seismic Resistant structures, identifying the primary parameters that govern the design[2][9], various control algorithms for optimization the damper design, mathematical modelling, simulation of damper using various Analytical systems[6][12]. This paper also focuses on the experimental investigation and validation of the analytical model.

\section{LITERATURE SURVEY}

A detailed review on various literatures has been carried out. Authors have derived various control algorithms for optimal design of MR dampers and have compared them analytically. Various Experimental investigations have been carried out by the Researchers for a predefined damping force [12]. Modelling of MR fluid damper has been done by varying the various parameters that affect the damping force, hence, to develop the most efficient damper [2], [4]. 
Magneto Rheological fluid is a colloidal suspension, consisting of magnetic nanoparticles with a carrier fluid like silicone oil. Its amazing magnetisable property has triggered the idea of developing the vibration damper by A. Ashfak, A. Saheed, K. K. Abdul Rasheed, and J. Abdul Jaleel [4] using MR fluids. He has carried out various experimental tests and evaluated its performance. In this paper, the Rheology of MR fluids and their use on vibration control were studied. The designed MR damper was tested using a Dynamic test rig and the results were obtained in the form of force v/s velocity and the force vs displacement plots. Furthermore, the experimental studies of a prototype magnetorheological damper at various magnitudes of control current have been carried out by E. Świtoński, A. Mężyk, S. Duda, S. Kciuk [3].This elaborated damper and applied control algorithms influenced the values of velocities and accelerations as obtained from the simulations. Hence, Incorporating this controllable damper into the stabilization system, it significantly reduced the displacements caused by structural excitations. These Semi-Active dampers change their damping force in real time by changing the damping coefficient according to the control policy. A number of semi-active control algorithms have been evaluated by K.Hudha, H.Jamaluddin, P.M.Samim and R.A.Rahman [14] to be used with MR damper. The effectiveness of these control algorithms in disturbance rejection along with their ability to consistently provide the target force in the same direction with the damper velocity to overcome the damper constraint have been investigated. YANG Yan, LI Hui, KANG Boseon [10] has derived equations of damping for MR damper in order to provide theoretical based foundations in the design of the damper. Based on these equation, the mathematical manipulation, the calculations of the volume, thickness and width of the annular MR fluids within the MR fluids damper are yielded and optimized. A semi-active control method for a seismically excited nonlinear benchmark building equipped with a MR damper is evaluated by Karamodin, H.H. Kazemiand M.R. Akbarzadeh[9]. He has proposed a Linear Quadratic Gaussian (LQG) controller design, to produce the optimal control force required by the damper. Further, the voltage required for the MR damper to produce the control force estimated by LQG controller is calculated by a Neural network predictive control algorithm (NNPC). Zhou Li, Chih- Chen Chang and B.F. Spencer [1] have developed two control strategies to protect buildings under dynamic hazards using semiactive control devices, MR dampers [19-22]. First strategy, gave the required output voltage to be supplied to the MR damper. It also provided a direct estimation of the voltage that is required to provide a target control force, calculated from some optimal control algorithms. Second strategy, involved the design of the fuzzy controller and an adaptation law for the combined building -MR damper system. These two approaches provided viable and effective means for controlling structures for seismic forces. The structures having the same damping capacity didn't provide effective results hence, using variable dampers new control algorithms were developed, where the active variable stiffness of the structure is adjusted to establish a non-resonant condition, whereas, active variable damper's damping coefficient is varied to achieve the reduced response due to seismic vibration.Three algorithms were developed by Fahim Sadek and Bijan Mohraz[15] namely LQR, a generalized LQR as well as displacement-acceleration domain algorithm, where the damping coefficient is selected in accordance to the response in the displacement-acceleration plane. An optimal design based strategy on genetic algorithms (GA) was proposed for nonlinear hysteretic control devices that prevented pounding effects of two adjacent structures. Also, an integrated fuzzy controller developed by Mehmet E. Uz, Muhammad N.S. Hadi [6] provided the interactive relationships between damper forces and input voltages for MR dampers based on the modified Bouc-Wen model. Furthermore, Linear Quadratic Regulator (LQR) and H2/LQG (Linear Quadratic Gaussian) controllers based on clipped voltage law (CVL) were also used to compare the results obtained by fuzzy controller. Aly Mousaad Aly [8] has developed a new control algorithm to command the MR damper. His approach was inspired by a Quasi-Bang-Bang controller. He has compared various control Algorithms and has formulated a new control algorithm that reduced the inter-storey drift to a 
greater extent as well as gave the highest reduction in the absolute floor accelerations. Design sensitivity analysis of damper parameters that governs the damper equation has been carried out by Henri Gavin, Jesse Hoagg and Mark Dobossy. They have also taken interest to compare MR damper with the Electro Rheological damper, in the context of electrical power requirements. Md.Sadak Ali Khan, A. Suresh and N. Seetha Ramaniah [2] have developed a mathematical finite element model for the MR dampers. They have examined and investigated the 2-D axi-symmetric MR damper model for Six different configurations of piston, which was simulated in ANSYS APDL to investigate how the shape of piston affects the maximum pressure drop of damper, the model with filleted ends gave the optimum pressure drop with respect to magnetic flux density. Hence, they concluded that higher loads could be carried by the damper even with a small capacity. It was found that having only shear mode or valve mode damper wasn't resulting efficient. Hence, a damper being designed as a hybrid mode like the Shear- Valve mode as suggested by Jagadish G. Kori and R.S. Jangid [5]. He has evaluated the effectiveness of input command voltage on MR damper system against the various proposed control laws. The performance of the MR dampers, different control algorithms with multiple MR damper locations were studied for real time earthquake records. Hence, he suggested the Shear-value mode to be the most efficient mode of the damper. Taking into consideration as the parameters of design and control algorithms, N.P.K.V. Karunaratne, D.P. Thambiratnam, and N.J. Perera [7] have generated a new codal requirements for incorporating MR dampers in building structures in order to obtain seismic performance that will satisfy current design codes and standards. Single ended piston of MR damper was incapable in taking up both compression and tension along the bracing. XU Long-he, LI Zhong-xian[11] has proposed a doubleended shear - valve mode MR damper, named MRF-04K damper, with the maximum force of $20 \mathrm{kN}$, and parameters of the Bouc-Wen hysteresis model were determined to portray the behavior of this damper. A 5-story building frame equipped with 2 MRF-04K were used as Benchmark problem. Currently, Double-ended MR dampers are becoming most efficient dampers used to control the seismic vibrations on structures.

\section{Operational Modes of MR Damper}

The Semi-Active Magneto-Rheological Fluid Damper can be operated in the following three modes: (i) Squeeze Mode (ii) Shear Mode (iii) Valve Mode

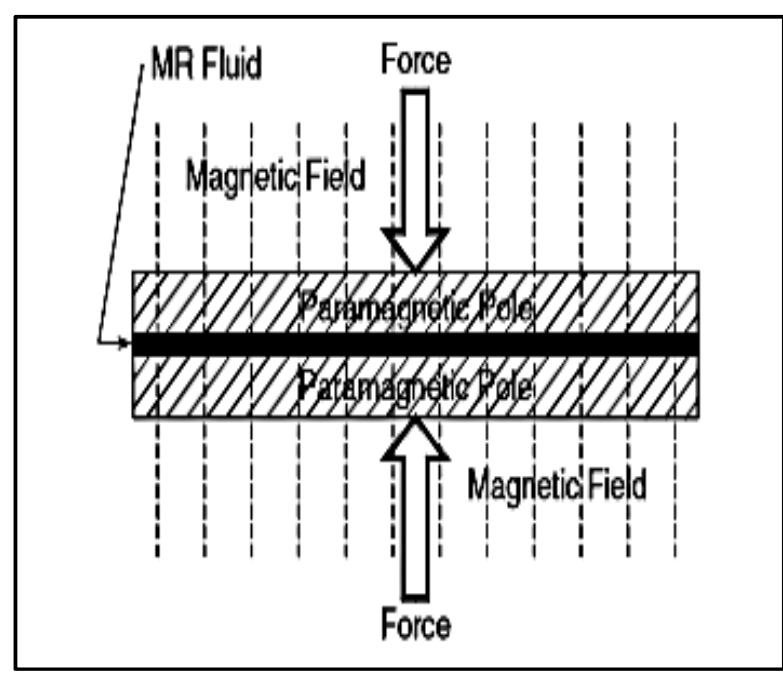

Figure 1: Squeeze Mode

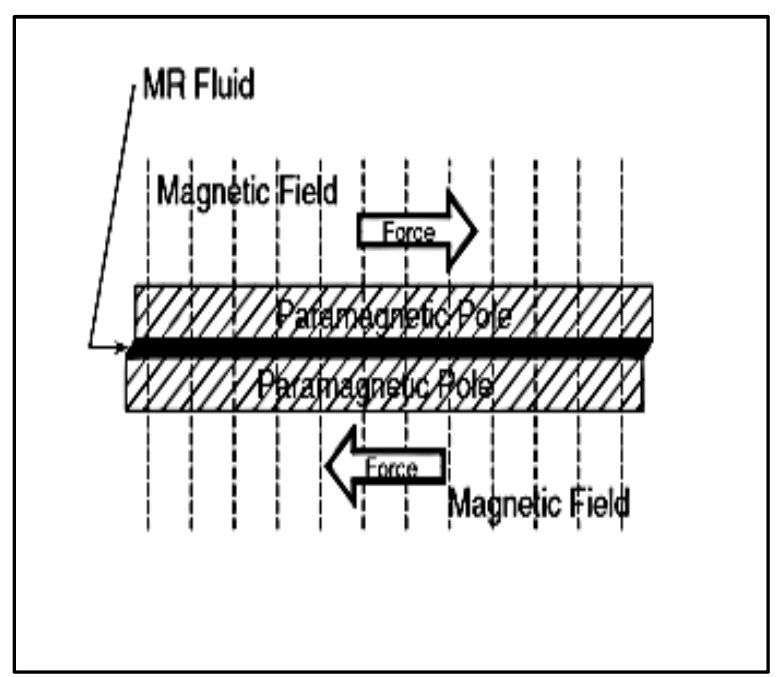

Figure 2: Shear Mode 


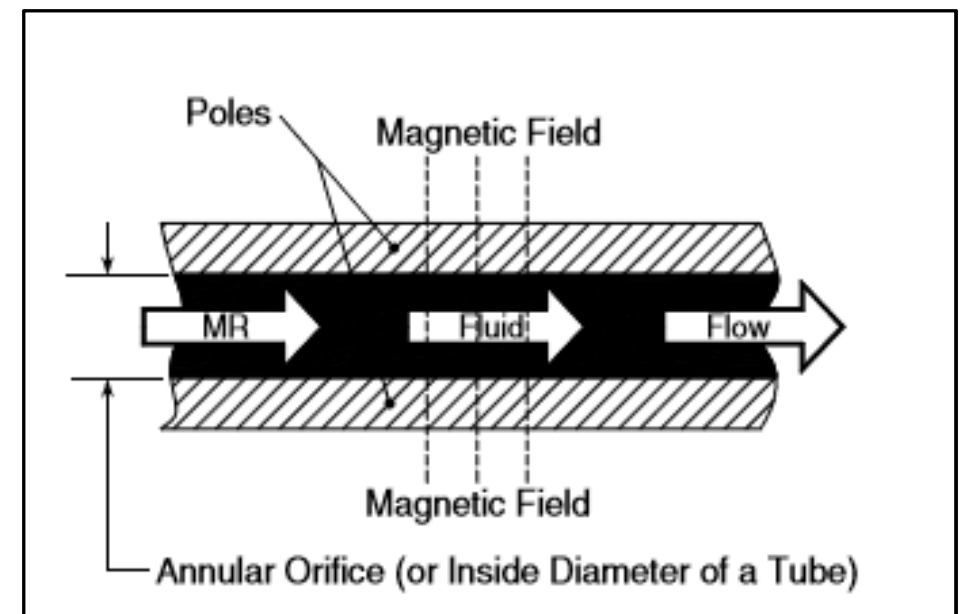

Figure 3: Valve Mode

Various Designs of MR Damper

The Dampers can be designed based on the Piston arrangement, and also based on the type of force the damper to resist. The various Designs of MR damper configurations are :

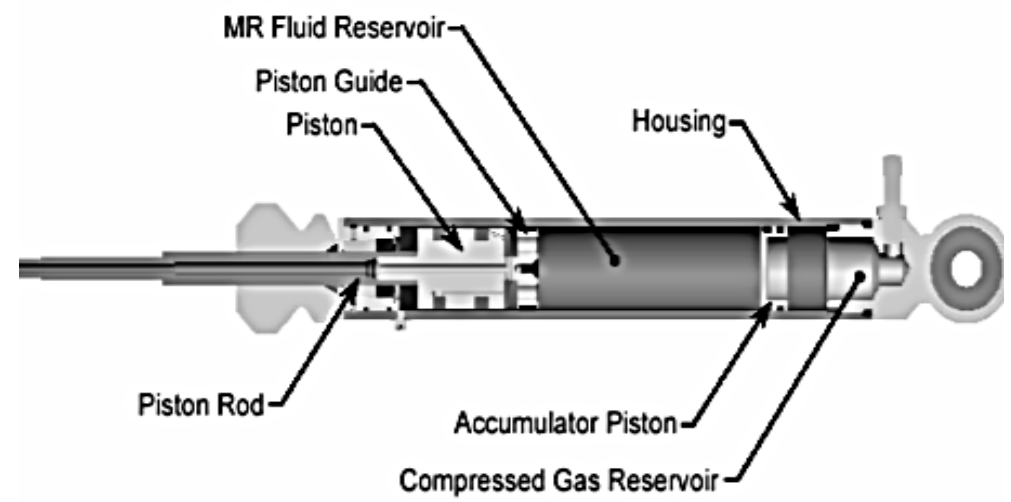

Figure 4: Single Ended Piston

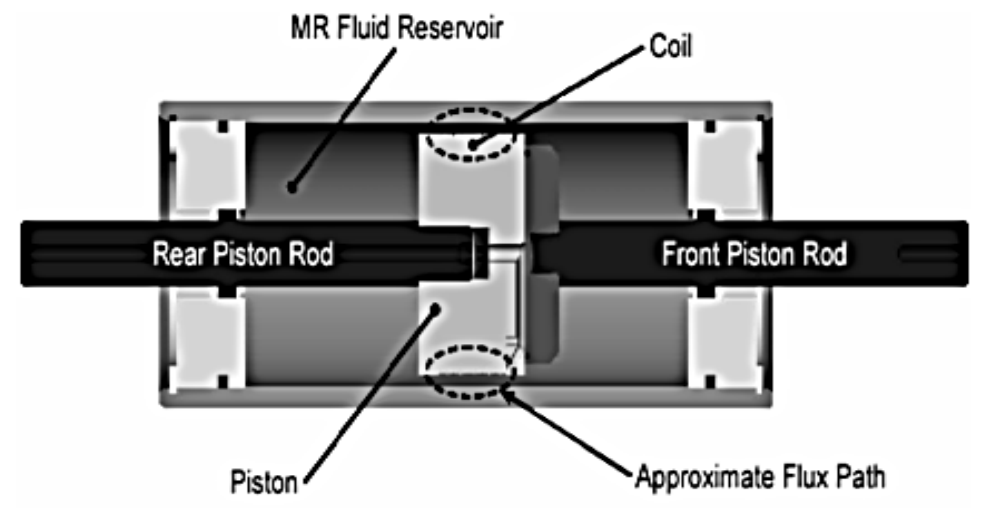

Figure 5: Double Ended Piston 


\section{VARIOUS MODELS OF MR DAMPERS}

\section{Bouc - Wen Model}

Various Researchers have proposed different models for MR dampers, to account for the dynamic behaviour of the damper having the damper force as a function of displacement and velocity across the damper and variation with the input current and voltage. The following are the various models :

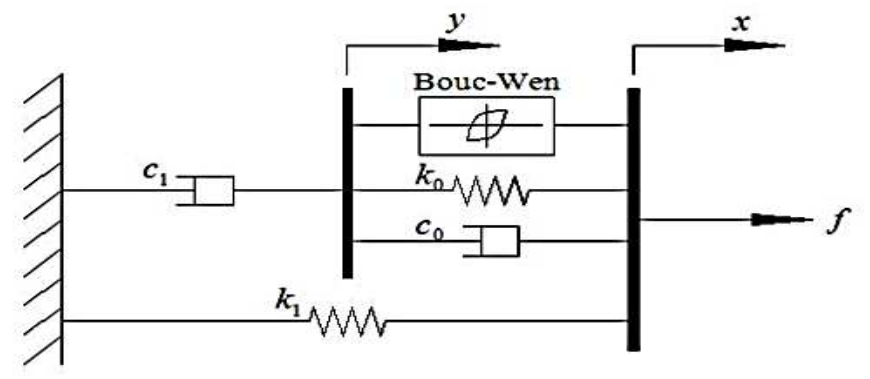

Figure 6: Bouc - Wen Model

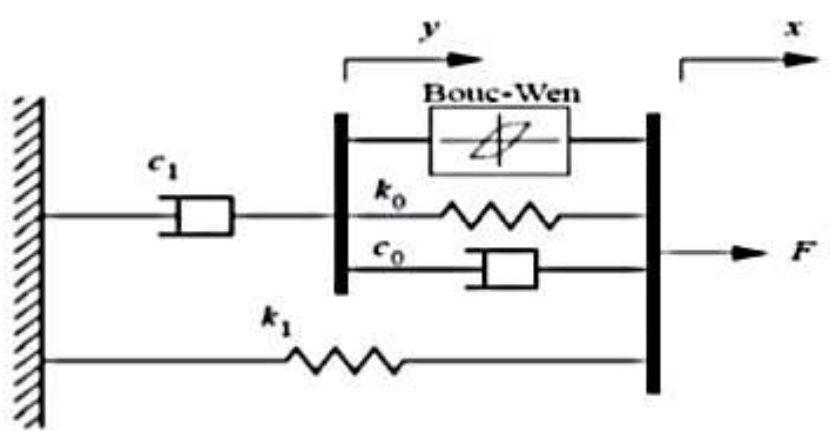

Figure 7: Modified Bouc-Wen Model Proposed by Spencer (1997)

$\mathrm{F}=\alpha \mathrm{z}+\mathrm{c} 0(\dot{\boldsymbol{x}}-\dot{\boldsymbol{y}})+\mathrm{k} 0(\mathrm{x}-\mathrm{y})+\mathrm{k} 1(\mathrm{x}-\mathrm{x} 0)$

The Force generated by MR damper for this model can be calculated by the following equation:

\section{Bingham Plastic Model}

A Bingham plastic model is characterized by dynamic yield stress. The shear stress can be expressed as,

Where, $\tau$ is shear stress of fluid in non

Newtonian stage,

$\tau y(B)$ is dynamic yield stress in applied magnetic field

$\mu$ is plastic viscosity independent of magnetic field,

$\gamma=(\mathrm{du} / \mathrm{dy})$ is shear rate of MR fluid

\section{Herschel - Bulkley Model}

Herschel-Bulkley model with a nonlinear relationship, which can be represented as,

$\tau x y=\tau y+K(d u / d y) n$ 
Where, $\tau y$ is shear yield stress,

$\mathrm{K}$ is consistency index or plastic viscosity,

$\mathrm{n}$ is flow behavior index:

$\mathrm{n}=1$ for Bingham fluid,

$\mathrm{n}<1$ for post yield shear thinning

$\mathrm{n}>1$ for post yield shear thickening

Algebraic Model proposed by Choi et al (2001)

An algebraic model consists of two components: a polynomial function, which describes the maximum damping force as a function of the control current, and a shape function describing the force velocity dependence.

$\operatorname{fmax}=\mathrm{m}|\dot{\boldsymbol{x}}|+\mathrm{b}$

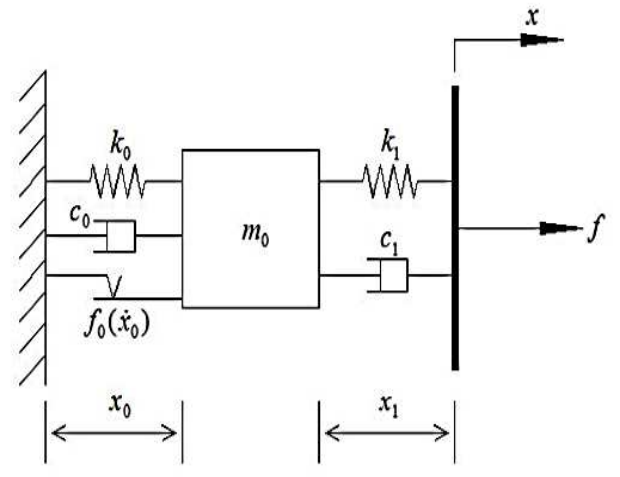

Figure 8: Hyperbolic Tangent Model

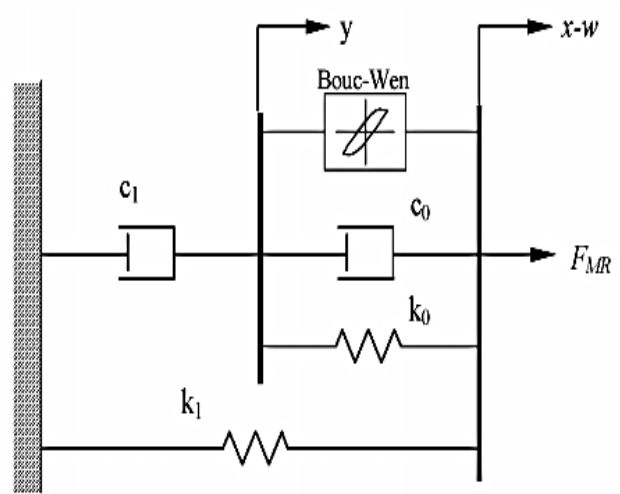

Figure 9: Spencer's Model

The reactive force exerted by the Damper is calculated as:

$\mathrm{FMR}=\mathrm{c} 1 \dot{\boldsymbol{y}}+\mathrm{k} 1(\mathrm{x}-\mathrm{w}-\mathrm{x} 0)$

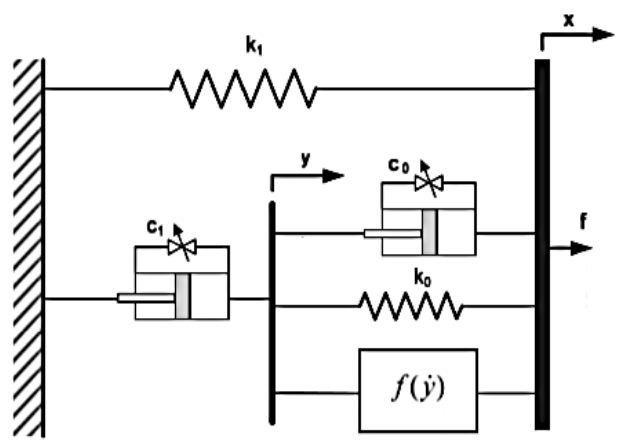

Figure 10: Spencers Mechanical Model

\section{SEMI-ACTIVE CONTROL ALGORITHMS}

The effectiveness of MR damper is analysed using various proposed Control Algorithms.:

$\operatorname{MS} \ddot{X}+\operatorname{CS} \dot{X}+\mathrm{KSX}=-\operatorname{MS} \wedge \ddot{X} \mathrm{~g}+\Gamma \mathrm{f}$ 
Where,

$\mathrm{Ms}$ is the mass matrix in $\mathrm{kg} \mathrm{Cs}$ is a damping matrix (in Ns/m)

$\mathrm{K} s$ is a stiffness matrix, $\mathrm{N} / \mathrm{m}$

$\ddot{x g}$ is a one-dimensional horizontal ground acceleration, $\mathrm{m} / \mathrm{s} 2$

$\Gamma$ is a matrix representing position of control forces

$\Lambda$ is a vector of ones

$\mathrm{f}$ is a vector of control forces, $\mathrm{N}$.

Various other algorithms proposed by various Researchers are given as:

\section{Clipped Optimal Algorithm}

It's the algorithm that has been shown to be most effective for the use, with the MR damper. It was proposed by Dyke, et al. (1996c-e). The clipped-optimal control approach is to design a linear optimal controller that calculates a vector of desired control forces based on the measured structural responses, and the measured control force vector applied to the structure.

\section{Bang - Bang Algorithm}

It is an on-off type of control algorithm: if the relative displacement and the relative velocity are in the same direction, then the command force is maximum; else, the command force is minimum.

\section{Skyhook Control Algorithm}

It is another on-off type of algorithm: if the relative velocity of the current story and the velocity of the earthquake induced ground motion are in the same direction, then the command force is maximum; else, the command force is minimum.

\section{Control Based on Lyapunov Stability Theory}

Leitmann (1994) applied Lyapunov's direct approach for the design of a semiactive controller. An infinite number of Lyapunov functions may be selected, that may result in a variety of control laws. Thus, in this algorithm, better performance is expected when measurements of the responses of the full structure are used.

\section{Decentralized Bang-Bang Control}

McClamroch and Gavin (1995) used a similar approach to develop the decentralized bang-bang control law for use, with an electrorheological damper. In this approach, the Lyapunov function was chosen to represent the total vibratory energy in the structure (kinetic plus potential energy)

\section{Maximum Energy Dissipation Algorithm}

This control algorithm is presented as a variation of the decentralized bang-bang approach. The resulting control law will command the maximum voltage, when the measured force and relative velocity are dissipating energy; and command the minimum voltage, when energy is not being dissipated. 


\section{Modulated Homogeneous Friction Algorithm}

This algorithm is considered herein, because there are strong similarities between the behaviour of a variable friction device and of the MR damper. In this approach, at every occurrence of a local extrema in the deformation of the device, the normal force applied at the frictional interface is updated to a new value. The normal force is chosen to be proportional to the absolute value of the deformation of the semi-active device.

\section{Groundhook Control Algorithm}

This algorithm was proposed by Karnopp and Crosby (1974) to reduce the response of vehicles further, and it was implemented in structures. Following Table was formulated using this algorithm:

Table I. Groundhook control logic

\begin{tabular}{lcc}
\hline Sign conventions & Damper conditions & Desired damping state \\
\hline$\dot{x}_{n-1}>0, \dot{x}_{r}<0$ & Extension & Off \\
$\dot{x}_{n-1}>0, \dot{x}_{r}>0$ & Compression & On \\
$\dot{x}_{n-1}<0, \dot{x}_{r}<0$ & Extension & On \\
$\dot{x}_{n-1}<0, \dot{x}_{r}>0$ & Compression & Off \\
\hline
\end{tabular}

\section{Proportional-Integral-Derivative Control (PID)}

A PID controller works on the basis of calculating appropriate control actions based on a calculated feedback error. For negative feedback control systems, the error defined as the difference of the output signal to a desired reference signal.

\section{Linear Quadratic Regulator Control (LQR)}

It was proposed by Soong in 1990. The LQR works on the basis of minimizing a quadratic performance index through manipulation and optimization of the control input.

\section{CONCLUSIONS}

From the review done based on the reference papers, the following conclusions were drawn: Optimizing the damper have been done mostly using control algorithms, and the validation of the results haven't been done experimentally. Analytical methods of optimization of the MR damper was done by considering the predefined damping force. Actual damping force is not taken into consideration for real time structures.

\section{ACKNOWLEDGEMENTS}

The authors thank the Karunya Institute of Technology and Sciences in Coimbatore,Tamil Nadu, India for their constant support. We also extend our acknowledgementto the Department of Science and Technology (Grant No : DST/TSG/STS/2015/30-G).

\section{REFERENCES}

1. Zhou, L., Chang, C. C., \& Spencer, B. F. (2002). Intelligent technology-based control of motion and vibration using MR dampers. Earthquake Engineering and Engineering Vibration, 1(1), 100-110.

2. Khan, M. S. A., Suresh, A., \& Ramaiah, N. S. (2012). Investigation on the performance of MR damper with various piston configurations. International Journal of Scientific and Research Publications, 2(12), 4. 
3. Świtoński, E., Mężyk, A., Duda, S., \& Kciuk, S. (2007). Prototype magnetorheological fluid damper for active vibration control system. Journal of Achievements in Materials and Manufacturing Engineering, 21(1), 55-62.

4. Ashfak, A., Saheed, A., Rasheed, K. A., \& Jaleel, J. A. (2011). Design, fabrication and evaluation of MR damper. International Journal of Aerospace and Mechanical Engineering, 1, 27-33.

5. Londoño, J. M., Neild, S. A., \& Wagg, D. J. (2015). Using a damper amplification factor to increase energy dissipation in structures. Engineering Structures, 84, 162-171.

6. Kori, J. G., \& Jangid, R. S. (2009). Semi-active MR dampers for seismic control of structures. Bulletin of the New Zealand Society for Earthquake Engineering, 42(3), 157.

7. Uz, M. E., \& Hadi, M. N. (2014). Optimal design of semi active control for adjacent buildings connected by MR damper based on integrated fuzzy logic and multi-objective genetic algorithm. Engineering Structures, 69, 135-148.

8. Karunaratne, N. P. K. V., Thambiratnam, D. P., \& Perera, N. J. (2016). Magneto-Rheological Dampers for Seismic Mitigation of Building Structures. Earthquake Struct, 11(6), 1001-1025.

9. Liu, B., \& Chen, J. (2011). Control system design of magneto-rheoloical damper under high-impact load. Modern Applied Science, 5(5), 253.

10. Aly, A. M. (2013). Vibration control of buildings using magnetorheological damper : a new control algorithm. Journal of Engineering, 2013.

11. Haji Kazemi, H., \& Akbarzadeh Totonchi, M. R. (2008, October). Semi-active Control of Structures Using Neuro-Predictive Algorithm for MR Dampers. In 14th world conference on earthquake engineering.

12. Jiang, Z., \& Christenson, R. (2011). A comparison of $200 \mathrm{kN}$ magneto-rheological damper models for use in real-time hybrid simulation pretesting. Smart Materials and Structures, 20(6), 065011.

13. Pătraşcu, M., Dumitrache, I., \& Pătruţ, P. (2012). A comparative study for advanced seismic vibration control algorithms. UPB Sci. Bull., Series C, 74(4), 3-16.

14. Hudha, K., Jamaluddin, H., Samin, P. M., \& Rahman, R. A. (2005). Effects of control techniques and damper constraint on the performance of a semi-active magnetorheological damper. International journal of vehicle autonomous systems, $3(2-4), 230-252$.

15. Sadek, F., \& Mohraz, B. (1998). Semiactive control algorithms for structures with variable dampers. Journal of Engineering Mechanics, 124(9), 981-990.

16. Gavin, H., Hoagg, J., \& Dobossy, M. (2001, August). Optimal design of MR dampers. In Proceedings of the US-Japan Workshop on Smart Structures for Improved Seismic Performance in Urban Regions (Vol. 14, pp. 225-236).

17. Mohebbi, M., Dabbagh, H. R., \& Shakeri, K. (2015). Optimal Design of Multiple Tuned Liquid Column Dampers for Seismic Vibration Control of MDOF Structures. Periodica Polytechnica Civil Engineering, 59(4), 543-558.

18. Jansen, L. M., \& Dyke, S. J. (2000). Semiactive control strategies for MR dampers: comparative study. Journal of Engineering Mechanics, 126(8), 795-803.

19. Hassaan, G. A. (2014). On simple tuning of PID controllers for underdamped second-order processes. International Journal of Mechanical and Production Engineering Research and Development, 4(3), 61-68. 
20. Vijaya kumar madura, babitha kodavanla, p srinivasa rao \& v madhavi (2018) Design and experimental study of semi active system of MR damper for vibration control, international journal of mechanical and production engineering research and development, 8(5), 125-132.

21. Nikam, H., Mishra, P., \& Bharambe, S. (2014). Design and Analysis of Brake Rotor with Parameter Optimization. International Journal of Automobile Engineering Research and Development (IJAuERD) Vol, 4, 21-30.

22. Daniel, C., Hemalatha, G., Magdalene, A., Tensing, D., \& Manoharan, S. S. (2017, May). Magnetorheological Damper for Performance Enhancement Against Seismic Forces. In International Congress and Exhibition" Sustainable Civil Infrastructures : Innovative Infrastructure Geotechnology" (pp. 104-117). Springer, Cham.

23. Solomon, S. M., Dharmaraj, T., Loganathan, S., Immanuel, S., Gladston, H., \& Cruze, D. (2018). Experimental Investigation on Magnetorheological Damper for RCC Frames Subjected to Cyclic Loading. Advances in Civil Engineering Materials, 7(3). 